\title{
Terapêutica da Osteoartrose - Buscando Novos Caminhos
}

\author{
Maxime Dougados*
}

\section{Definição}

Os Comitês da Liga Internacional Contra o Reumatismo, da Sociedade de Pesquisa da Osteoartrite e da Organização Mundial da Saúde recentemente consideraram orientações para testar novas drogas atuando na osteoartrite: terapia de ação rápida sobre os sintomas, terapia de ação lenta sobre os sintomas e drogas modificadoras da doença.

Foram feitas duas distinções nesta classificação:

- A primeira é a distinção entre a terapia sintomática e a terapia modificadora da doença. Esta distinção origina-se do fato de que a correlação entre a severidade da dor na articulação e/ ou incapacidade e as mudanças patológicas na articulação osteoartrítica é muitas vezes pequena. Além disso, uma correlação negativa pode ser observada, isto é, uma melhora nos sintomas clínicos com uma deterioração nas mudanças patológicas.

- A segunda é a distinção entre as drogas de ação rápida e lenta. Diversos argumentos poderiam ser elencados a favor da criação destas duas classes de drogas, mas nenhum é especialmente preponderante. Poder-se-ia argumentar, por exemplo, que devido à sua lenta atuação, as drogas de ação lenta devem ter um mecanismo de ação diferente daquele dos analgésicos ou NSAIDs. O modelo do estudo e, particularmente, a sua duração e a terapia concomitante diferem de acordo com o suposto início da ação da droga.

O conceito de modificação da doença é muito fácil de compreender. Todos concordam que uma terapia capaz de "modificar" a doença será capaz de impedir o resultado insatisfatório, de longo prazo, da doença. Entretanto, a aplicação deste conceito na pesquisa clínica prática é muito mais complicada. Não há uma definição clara de resultado clínico de longo prazo, e a progressão clínica natural da doença tem um processo muito lento para ser pesquisada na prática. Entretanto, uma vez que alguns dados sugerem, fortemente, que este resultado de longo prazo está correlacionado com mudanças anatômicas observadas na osteoartrite, admite-se que uma terapia que seja capaz de influenciar o progresso anatômico da osteoartrite seria considerada como um "tratamento modificador da doença". 
Esta definição sugere que se efetuem estudos clínicos epidemiológicos de duas maneiras: o primeiro para fornecer ferramentas acuradas que permitam avaliar as mudanças anatômicas da doença; o segundo para definir os subgrupos de pacientes nos quais o progresso anatômico da doença é particularmente rápido.

\section{Fatores de previsão da progressão da osteoartrite}

Diversos estudos clínicos epidemiológicos enfatizaram que tais fatores de previsão realmente existem e estão relacionados à localização da $\mathrm{OA}$, isto é, fatores de risco para a progressão da OA do quadril são diferentes daqueles da OA do joelho. Um amplo estudo epidemiológico de um ano de duração, conduzido em 508 pacientes sofrendo de osteoartrite dolorosa do quadril, permitiu identificar alguns fatores de risco relacionados à progressão radiológica. Nesse estudo, a progressão radiológica foi definida por uma mudança de pelo menos $0,6 \mathrm{~mm}$ na distância interóssea avaliada no ponto mais estreito, pela utilização de uma lente de aumento. Fatores relacionados tanto com dados demográficos (idade, gênero), localização (migração superolateral da cabeça do fêmur), severidade (amplitude do espaço da articulação menor do que $2 \mathrm{~mm}$ ), quanto com atividade da osteoartrite (índice de Lequesne acima de 10) foram correlacionados com a progressão radiológica acima definida.

No nível do joelho, a progressão da doença pode ser definida por uma mudança na severidade da condropatia avaliada na artroscopia. Estudos efetuados utilizando tal metodologia permitiram confirmar o gênero e a severidade da osteoartrite como fatores de predisposição da progressão. Além disso, estes estudos permitiram identificar dois outros fatores (presença de sinovite e nível elevado de ácido hialurônico no soro) como fatores de predisposição de rápida progressão anatômica.

\section{Resultado das medições}

Diversos estudos estão em andamento com o objetivo de avaliar as principais características de uma medição relevante (isto é, validade, confiabilidade, sensibilidade para a mudança, capacidade discriminante...) para diferentes ferramentas propostas, permitindo avaliar a progressão anatômica da doença (isto é, raios- $X$, artroscopia, MRI...).
A artroscopia é uma técnica agressiva. Entretanto, uma simplificação desta técnica (procedimento com pacientes de ambulatório, anestesia local, ausência de torniquete) chamada condroscopia permite, atualmente, sugeri-la como um resultado potencial de medição da osteoartrite. Além disso, um sistema de escores da severidade da condropatia mostrou preencher as principais características de um resultado de medição.

Diversos estudos recentes pesquisaram os raios-X simples, com o objetivo de considerá-los como ferramenta acurada para avaliar a osteoartrite. Todos os estudos enfatizam a necessidade de uma padronização do procedimento radiológico e do posicionamento do paciente. Além disso, diversas técnicas estão avaliando os diferentes aspectos das mudanças articulares observadas na osteoartrite (osteofitos, estreitamento do espaço da articulação etc.). Portanto, os raios- $X$ simples devem ser considerados como uma nova ferramenta para a avaliação da osteoartrite.

\section{Experimentos clínic os com a diacereína e o ácido hialurônico}

\section{Ácido hialurônico}

A razão para a utilização do ácido hialurônico no tratamento da osteoartrite em seres humanos baseia-se não apenas nas descobertas de que a viscoelasticidade do fluido sinovial é inteiramente devida ao seu conteúdo de ácido hialurônico e que o ácido hialurônico forma uma parte integral dos proteoglicanos da cartilagem articular, mas também na evidência de que o ácido hialurônico pode influenciar a doença pela interação com os componentes do fluido sinovial e a cavidade sinovial.

Em nosso departamento, efetuamos dois experimentos clínicos com hyalectin, que é uma solução viscosa concentrada, altamente purificada $(10 \mathrm{mg} / \mathrm{ml})$, de elevado peso molecular (500-730 $\mathrm{kDa}$ ) de hialuronato de sódio extraído de Cristas de Galo e desenvolvida para o uso terapêutico em seres humanos.

O primeiro experimento foi esboçado para avaliar o efeito sintomático clínico das injeções intra-articulares de hyalectin. Para este propósito, nós efetuamos um experimento prospectivo, randomizado, controlado por placebo, de um ano de duração, em 110 pacientes com osteoartrite hidrartrodial dolorosa do joelho. Na admissão e uma vez por semana, durante três semanas, foram realizadas a aspiração da efusão do joelho e a injeção intra-articular do hyalectin ou do seu veículo. As conclusões foram as seguintes: 
- Há um efeito sintomático benéfico, estatisticamente significativo, das injeções intra-articulares do hyalectin, quando comparado com o placebo,

- O início da ação parece ocorrer três a quatro semanas após o começo da terapia,

- Um efeito prolongado foi observado durante o acompanhamento de um ano deste estudo.

$\mathrm{O}$ segundo experimento foi esboçado para avaliar o efeito anatômico das injeções intraarticulares do hyalectin. Com esse objetivo, efetuamos um experimento prospectivo, randomizado, controlado, de um ano de duração, em 29 pacientes com osteoatrite dolorosa do joelho. Na linha basal e após um ano, foi realizada uma condroscopia para permitir a avaliação da severidade anatômica da condropatia. Durante este ano de estudo, o hyalectin foi administrado uma vez por semana durante duas semanas (três injeções) a cada três meses ( 3 ciclos $=9$ injeções). A análise em cego das descobertas artroscópicas mostra uma deterioração da severidade da condropatia em ambos os grupos. Entretanto, esta deterioração foi, em termos estatísticos, significativamente menos importante no grupo de pacientes recebendo o hyalectin quando comparada com o grupo de controle. Portanto, esse estudo sugere que as injeções interativas intra-articulares de hyalectin podem ter um efeito benéfico de modificação da doença osteoartrítica.

\section{Diacereína}

Testes farmacológicos mostraram que a Diacereína pode reduzir o edema induzidocarragenina e que ela possui propriedades antipiréticas e antinociceptivas. A Diacereína tem alguns efeitos benéficos em modelos animais de doenças reumáticas inflamatórias e efeitos benéficos marcantes em modelos animais de osteoartrites.

O mecanismo de ação da Diacereína é diferente daquele descrito para drogas antiinflamatórias não-esteroidais ou corticosteróides.
A Diacereína tem a habilidade de estimular a síntese de prostaglandinas em culturas de condrócitos humanos.

Outros estudos in vitro têm demonstrado que a Diacereína inibe os efeitos da interleucina-1 sobre os condrócitos.

Os estudos clínicos a tempos conduzidos com a Diacereína têm estabelecido:

- um efeito sintomático estatisticamente significante (avaliado sobre a dor e incapacidade funcional) quando comparado ao placebo;

- o aparecimento da ação em termos da melhora dos sintomas clínicos ocorre de quatro a seis semanas após o início da terapia;

- o tempo em que o platô de eficácia é alcançado (em termos de sintomas) carece de investigação;

- após suspensão, uma dilatação clínica é observada, porém, somente após uma certa demora ( \pm 30 dias), sugerindo um efeito sintomático de transporte da droga.

Dois experimentos clínicos em andamento estão avaliando um efeito potencial de condromodulação da Diacereína:

- o estudo ECHODIAH é um estudo randomizado, controlado por placebo, de três anos de duração, em 507 pacientes sofrendo de osteoartrite do quadril. Neste estudo, a variável resultante principal é definida pelas mudanças no estreitamento do espaço da articulação sob o ponto de vista radiológico;

- o estudo condroscópico é um estudo randomizado, controlado por placebo, de um ano de duração, em 60 pacientes sofrendo de osteoartrite do joelho. Neste estudo, a variável resultante principal é definida pelas mudanças na severidade da condropatia avaliadas na condroscopia. 